\title{
CORVALLIS, OREGON, CRUSTAL AND UPPER MANTLE RECEIVER STRUCTURE FROM TELESEISMIC $P$ AND $S$ WAVES
}

\author{
By Charles A. Langston
}

\begin{abstract}
Structure under Corvallis, Oregon, was examined using long-period $P s$ and $S p$ conversions and $P$ reverberations from teleseismic events as recorded at the WWSSN station COR. A distinct low-velocity zone in the uppermost mantle is inferred by modeling these phases in the time domain using a data set composed of six deep and intermediate-depth earthquakes. The lower boundary occurs at $45-\mathrm{km}$ depth and has $S$ and $P$ velocity contrasts of 1.3 and $1.4 \mathrm{~km} / \mathrm{sec}$, respectively. The material comprising the low-velocity zone has a Poisson ratio of at least 0.33 and is constrained by the average $P$ and $S$ travel times determined from the converted phases. The top of the earth model conforms to previously published refraction results.
\end{abstract}

\section{INTRODUCTION}

The distinct low-velocity zone found for the Puget Sound upper mantle (Langston and Blum, 1976) suffers uniqueness problems since it is based on interpretation of earthquake seismograms. The hypotheses testing approach used in that study does not guarantee that the assumptions are correct, even though good fits were obtained for the data. To test the inferred earth model, an independent data set of teleseismic $P$ and $S$ waves recorded at the WWSSN station COR, Corvallis, Oregon (Figure 1) was utilized to model interfaces under the station. These boundaries were inferred from phase conversions, such as $P s$ and $S p$, that they produce. This study should also form a basis for other similar studies in the Pacific Northwest.

\section{Method}

The procedure for deducing crustal and upper mantle structure using one threecomponent long-period station is basically very straightforward. Long-period $P$ and $S$-wave observations from deep and intermediate teleseismic $\left(\Delta>30^{\circ}\right)$ events are modeled in the time domain for directly observable structure phases such as $P s$ and $S p$. We will assume that the Earth can be represented by a series of plane homogeneous elastic layers and that waves impinging below the structure are sufficiently far from their source so they can be considered plane waves. These plane $P$ and $S$ waves are described by one ray parameter appropriate for the source distance and depth.

Ray theory will be relied upon to furnish direct interpretations concerning the relative arrival times and amplitudes of particular phases. Ray paths are specified through a particular model and the usual transmission and reflection coefficients are used to find the amplitude (Helmberger, 1968).

To find the total response for a relatively complicated model, the ray approach becomes unwieldly because of ray summation. Layer matrix techniques become convenient since they can solve the entire problem without recourse to complicated and lengthy ray descriptions. The solution for displacements at the free surface for impinging $P$ and $S$ plane waves in a half-space below a stack of layers is well known and is given by Haskell $(1960,1962)$. His expressions are evaluated in the frequency 
domain, and multiplied with a suitable source time history, instrument, and attenuation operator. This total response is then transformed into the time domain via the Fast Fourier Transform.

Many investigators have approached this type of modeling problem by making extensive use of spectral amplitude ratios (Hannon, 1964; Phinney, 1964; Fernandez, 1967; Leblanc, 1967; Fernandez and Careaga, 1968; Bonjer et al., 1970; Kurita, $1973 \mathrm{a}, 1973 \mathrm{~b}$; Leong, 1975). In this technique the spectral ratio of radial to vertical $P$-wave components is found using an arbitrary teleseismic earthquake source. This

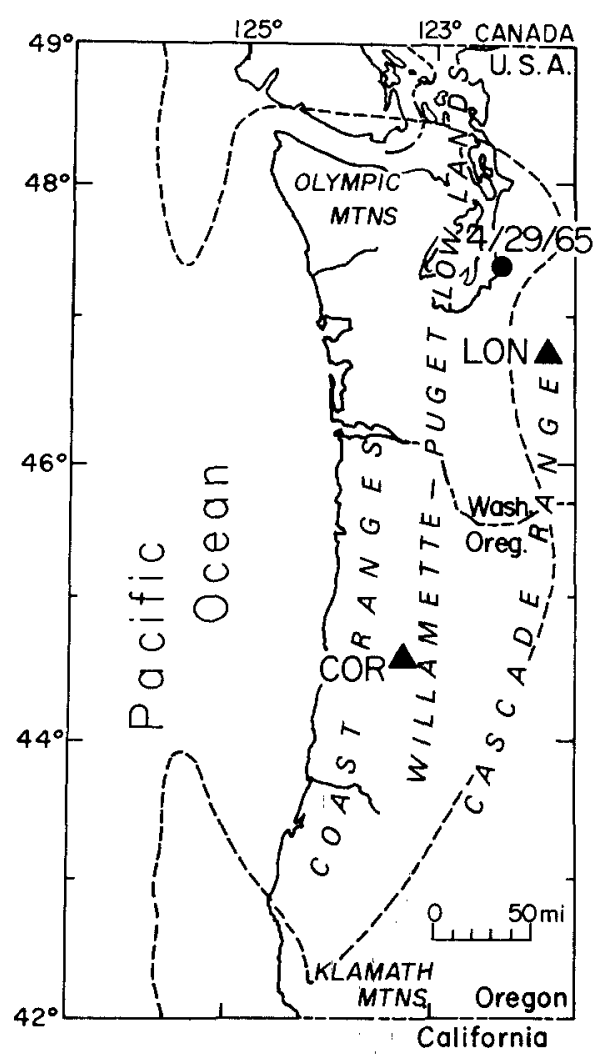

FIG. 1. Index map of western Washington and Oregon showing the epicenter of the 1965 Puget Sound event and WWSSN stations used in the receiver structure determination. The dashed line is the approximate extent of the Tertiary eugeosyncline, after Snavely and Wagner (1963).

essentially deconvolves the source function from the observations since it should be common to each component, assuming they have matched instrument responses. The observed amplitude ratios are then compared to theoretical ratios for several types of crustal models. Although this method removes the source function, it has the drawbacks of all spectral interpretations. It is exceedingly hard to study the timing and amplitude of individual phases in the frequency domain and to directly interpret the spectral ratio. The added uncertainties of truncation errors and digital noise add to the confusion since taking a spectral ratio may be a very unstable process. We will therefore take the approach of directly modeling the observations, both $P$ and $S$ waves, in the time domain by using estimates of the incident source function. All assumptions are clearly presented, as pointed out by Burdick and Langston (1976), and are directly observable through the synthetic seismogram. The radial and vertical 
$P$ components and vertical $S V$ components will be used extensively in the interpretations to follow. Recently, Jordan and Frazier (1975) investigated $S p$ precursors using this time-domain approach although they made no use of the $P$ waves.

To illustrate what types of structure effects distort incident $P$ and $S$ waves, let us examine a simple one-layer model over a half-space. Figure 2 displays responses for several earth models, whose parameters are listed in Table 1.

All of the seismograms of Figure 2 were computed using the layer matrix formulation have a 15-100 instrument response and have a simple isosceles triangular time function $2 \mathrm{sec}$ in duration included. The attenuation parameters $(T / Q)$ (Carpenter, 1966) assumed for $P$ and $S$ waves were 1.0 and 4.0, respectively. Values of 0.06 and $0.1 \mathrm{sec} / \mathrm{km}$ were used for the $P$ and $S$ ray parameters, respectively, and are appro-

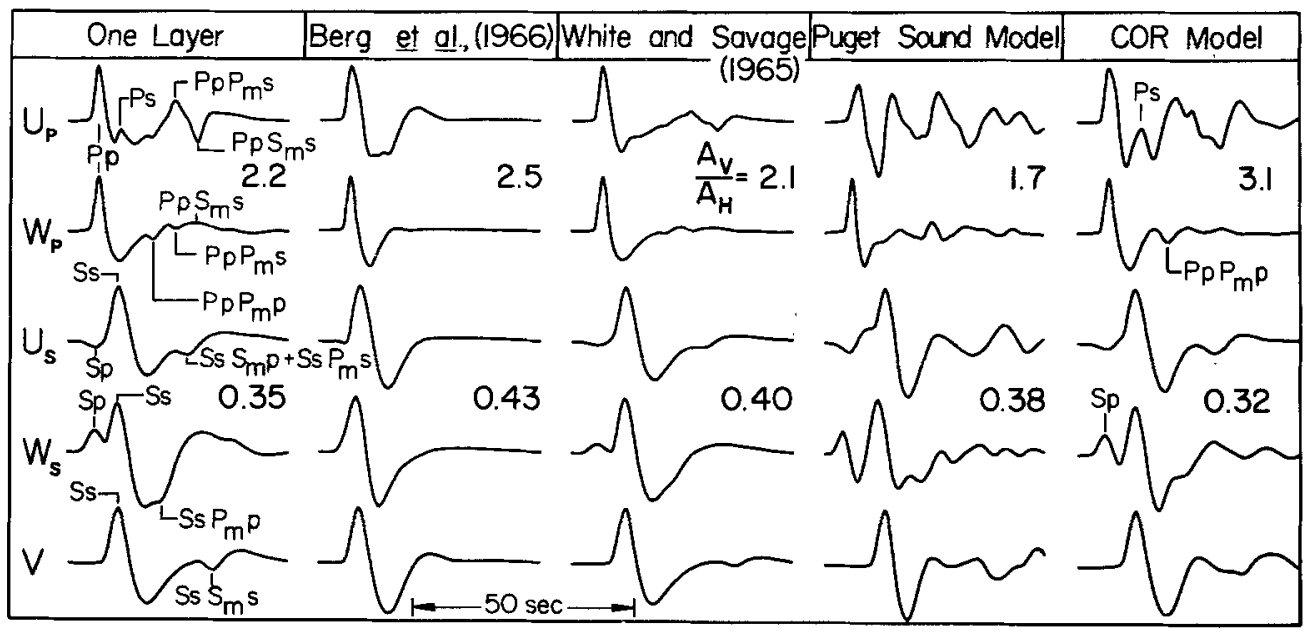

FIG. 2. Synthetic seismogram calculations for all $P$ - and $S$-wave components for the earth models of Table 1 . Under each heading are shown the radial $P$, vertical $P$, radial $\$ V$, vertical $S V$, and tangential $S H$ displacement components designated by $U_{p}, W_{p}, U_{s}, W_{s}$, and $V$, respectively. Arrival times of individual rays are designated and described using the notation of $B$ anth and Stefánsson (1966). The numbers correspond to the vertical/horizontal amplitude ratio for the $P$ and $S V$ waves.

priate for a source range of $60^{\circ}$. Examining the horizontal and vertical $P$ waves of the one-layer model immediately indicates the relative complexity between these components and where most of the structure information lies. Since the incident angle for teleseismic $P$ waves is relatively steep, $P$ to $S$ conversions should be predominant on the radial component rather than the vertical. This is very apparent in the ray descriptions. The notation used in describing ray paths for the one-layer model is adopted from Bath and Stefánsson (1966). The first capital letter, $P$ or $S$, designates the incident wave. Lowercase letters refer to upgoing waves in the layer and subsequent capitals refer to the downgoing wave. The subscript " $m$ " refers to a reffection at the moho, or the 8.1 to $6.0 \mathrm{~km} / \mathrm{sec}$ boundary. The major phases occurring on the horizontal $P$ component are the $P \&$ conversion at the moho and subsequent $P$ reverberations with the final ray legs spent in the $S$ mode. The vertical $P$ wave is relatively undistorted with the first $P$ reverberation producing the largest later arrival. The most important phase in the $S V$ components, other than the direct wave, is the $S p$ precursor. Since $S p$ is largest on the vertical $S V$ component, this 
component should be used for its interpretation, as pointed out by Jordan and Frazier (1975). $S H$ waves are relatively uninteresting with the only major crustal effect occurring far back in the record. Since the effect is small and this part of the $S$ record usually noisy, the $S H$ waves will not be utilized in the structure inversions.

TABLE 1

Earth Models

\begin{tabular}{|c|c|c|c|c|}
\hline Layer No. & $\begin{array}{c}V_{p} \\
(\mathrm{~km} / \mathrm{sec})\end{array}$ & $\begin{array}{c}V_{s} \\
(\mathrm{~km} / \mathrm{sec})\end{array}$ & $\begin{array}{c}\rho \\
(\mathrm{gm} / \mathrm{cc})\end{array}$ & $\begin{array}{c}T h \\
(\mathrm{~km})\end{array}$ \\
\hline \multicolumn{5}{|c|}{ Model of One-Layer over Half-space } \\
\hline 1 & 6.0 & 3.5 & 2.6 & 40.0 \\
\hline 2 & 8.1 & 4.7 & 3.2 & - \\
\hline \multicolumn{5}{|c|}{ Oregon Coast Range Model (Berg et al., 1966) } \\
\hline 1 & 4.4 & $2.5^{*}$ & $2.5^{*}$ & 2.2 \\
\hline 2 & 5.5 & 3.0 & 2.6 & 7.7 \\
\hline 3 & 6.6 & 3.8 & 2.8 & 3.8 \\
\hline 4 & 7.4 & 4.2 & 3.0 & 2.1 \\
\hline 5 & 8.0 & 4.6 & 3.2 & 10.0 \\
\hline Vancouver & Island $M$ & del (Whit & and $\mathrm{Sa}$ & ge, 1965) \\
\hline 1 & 6.0 & $3.5^{*}$ & $2.7^{*}$ & 6.2 \\
\hline 2 & 6.73 & 3.9 & 2.8 & 45.0 \\
\hline 3 & 7.74 & 4.5 & 3.1 & 一 \\
\hline \multicolumn{5}{|c|}{ Puget Sound Model } \\
\hline 1 & 2.0 & 1.0 & 2.5 & 1.2 \\
\hline 2 & 3.0 & 1.5 & 2.5 & 1.2 \\
\hline 3 & 4.5 & 2.3 & 2.5 & 2.5 \\
\hline 4 & 6.8 & 3.9 & 2.9 & 4.0 \\
\hline $\mathbf{5}$ & 7.4 & 4.2 & 3.0 & 4.5 \\
\hline 6 & 7.8 & 4.3 & 3.2 & 27.3 \\
\hline 7 & 6.5 & 3.1 & 2.9 & 7.0 \\
\hline 8 & 5.5 & 2.9 & 2.7 & 8.0 \\
\hline 9 & 8.0 & 4.6 & 3.2 & 一 \\
\hline \multicolumn{5}{|c|}{ Corvallis Model } \\
\hline 1 & 5.5 & 3.0 & 2.6 & 10.0 \\
\hline 2 & 6.7 & 3.9 & 2.8 & 6.0 \\
\hline 3 & 8.0 & 4.6 & 3.2 & 5.0 \\
\hline 4 & 7.9 & 4.5 & 3.15 & 1.5 \\
\hline 5 & 7.8 & 4.2 & 3.1 & 2.0 \\
\hline 6 & 7.7 & 3.7 & 3.0 & 1.5 \\
\hline 7 & 7.5 & 3.5 & 2.95 & 1.5 \\
\hline 8 & 7.2 & 3.3 & 2.9 & 2.0 \\
\hline 9 & 6.9 & 3.3 & 2.85 & 2.5 \\
\hline 10 & 6.6 & 3.3 & 2.85 & 12.9 \\
\hline 11 & 8.0 & 4.6 & 3.2 & - \\
\hline
\end{tabular}

* Assigned $S$ velocities and densities for this study.

Because we will be doing direct interpretations of the data by comparison with time-domain synthetic seismograms, the source function of the incident wave will have to be estimated. In general, however, it is hardly ever known. To minimize this problem, only deep and intermediate-depth earthquakes will be used so that free-surface and other near-source complications are avoided. Furthermore, a group of several events rather than a single event will be studied to make sure that interpreted structure effects are consistent over the entire data set. The earthquake data set is chosen on the basis of favorable signal-to-noise ratio and simplicity of the 
wave form. Earthquakes which have vertical $P$ wave forms containing two or more obvious pulses are avoided. The vertical $P$ wave is used for this decision on the basis of the one-layer theoretical study of Figure 2. The vertical $P$ wave is also used to find an estimate for the effective source time function by examination of the instrumental deconvolution and through trial and error wave-form fitting (Burdick and Langston, 1976). Note that, although the effective source time function is a relatively unknown quantity, it is common to both vertical and radial components. The comparison of these components in terms of the complexity of the radial component to the theoretical simplicity of the vertical component forms the basis for interpreting structure phases. Adjustment of the effective source function to fit the data must be done within this constraint and is, in general, not arbitrary.

\section{Data AND Data Interpretation}

A search of the WWSSN data for COR along the above guidelines yielded the earthquakes listed in Table 2. Not every wave type or component was used from each earthquake depending on its range and signal-to-noise ratio. For example, the

TABLE 2

Epicenter Parameters (ISC)

\begin{tabular}{rrrcccccl}
\hline Date & Time & Lat. (deg) & Long. (deg) & $M_{b}$ & $h$ & $\begin{array}{c}\Delta \\
(\mathrm{deg})\end{array}$ & $\begin{array}{c}\text { BAZ } \\
(\mathrm{deg})\end{array}$ & \multicolumn{1}{c}{ Location } \\
\hline $11 / 3 / 65$ & $01: 39: 03.2$ & $9.10 \mathrm{~S}$ & $71.40 \mathrm{~W}$ & 6.2 & 583 & 71.0 & 124.7 & Peru-Brazil \\
$2 / 15 / 67$ & $16: 11: 11.8$ & $9.05 \mathrm{~S}$ & $71.34 \mathrm{~W}$ & 6.1 & 598 & 71.0 & 124.7 & Peru-Brazil \\
$9 / 9 / 67$ & $10: 06: 44.5$ & $27.62 \mathrm{~S}$ & $63.15 \mathrm{~W}$ & 5.9 & 577 & 90.4 & 129.7 & Argentina \\
$12 / 27 / 67$ & $9: 17: 50.3$ & $21.29 \mathrm{~S}$ & $68.20 \mathrm{~W}$ & 6.3 & 91 & 82.6 & 129.5 & Chile \\
$1 / 19 / 69$ & $7: 02: 07.9$ & $44.89 \mathrm{~N}$ & $143.21 \mathrm{E}$ & 6.3 & 238 & 62.5 & 306.9 & Japan \\
$1 / 29 / 71$ & $21: 58: 03.2$ & $51.69 \mathrm{~N}$ & $150.97 \mathrm{E}$ & 6.0 & 515 & 54.5 & 310.3 & Sea of Okhotsk \\
\hline
\end{tabular}

9/9/67 event was clear on the vertical $P$ component, but the horizontal $P$ wave was in the noise because of the earthquake's large range. The data wave forms were digitized according to the methods of the previous studies (Langston and Blum, 1976). Because the station was not naturally rotated, with respect to the ray directions, the horizontal $P$ waves were rotated into the theoretical back azimuths to get the radial component. This process was successful in all cases judging by the close agreement between the amplitude levels of the "tangential" $P$ wave and the noise before the signal. This implies that nonhorizontal structure is not a large effect (Langston, 1976).

The data and corresponding synthetics for the final model are presented in Figures 3,4 , and 5. For each wave-form pair the observed is on top and the synthetic displayed directly below. To the left of these traces is the effective time function used in computing the synthetics. The final Corvallis earth model is presented in Figure 6 and listed in Table 2. Again, as in the Puget Sound study, both the wave-form fits and the earth model have several striking characteristics. The wave fits are generally excellent and reproduce the main observed effects. The earth model is again very unusual in that it has an extensive LVZ in the uppermost mantle with a high contrast lower boundary.

The modeling process which produced this final earth structure can most easily be explained by returning to Figure 2 which displays the comparison of several synthetic models. The model of Berg et al. (1966) should be most appropriate since they 
used the station COR in their study. However, this model does not predict any of the phase conversions or reverberations seen in the data. Compare the $P$ waves of the 12/27/67 event in Figure 3 with this model, for example. Although these phases are produced by the laver interfaces, the total crustal thickness, and hence, travel

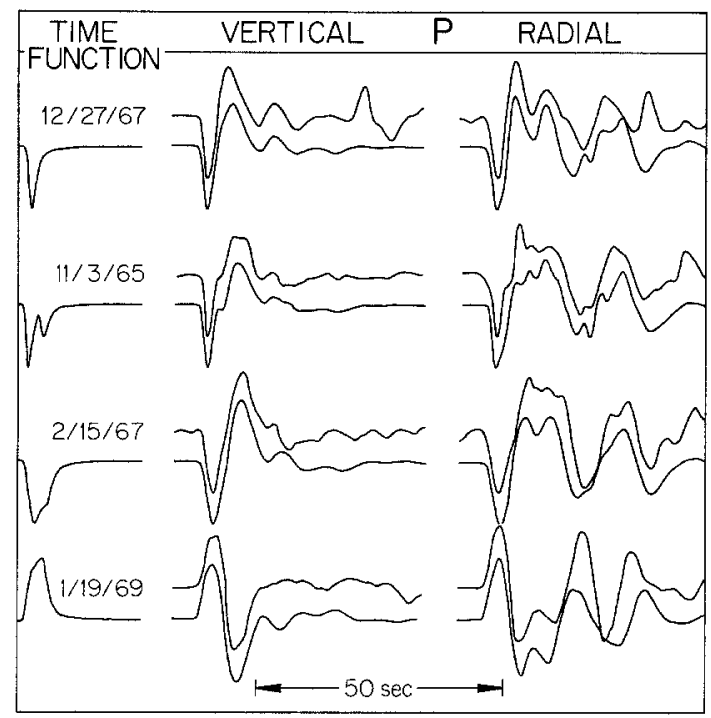

FIG. 3. Comparison of observed and final synthetic wave forms for the horizontal and vertical $P$-wave components. The observed is on top for each component. To the left of each verticalhorizontal set is the effective time function that was used in the synthetic calculation.

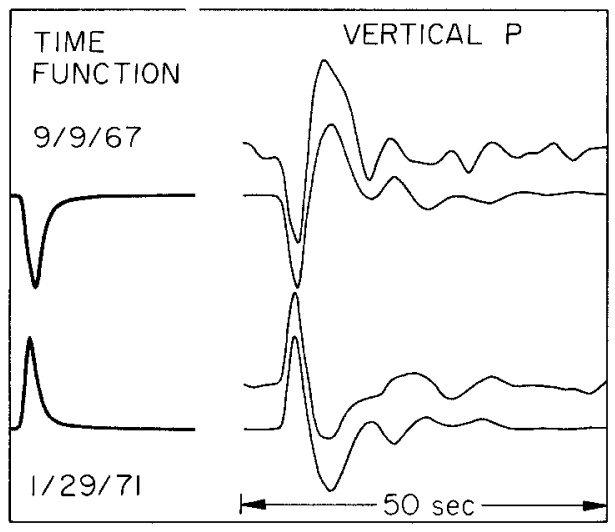

FIG. 4. Comparison of observed and final synthetic wave forms for the vertical $P$ component from two earthquakes. Same scheme as Figure 3.

time, is too small for them to be directly observable. The model of Vancouver Island by White and Savage (1965), although thicker, still does not produce the desired amplitudes for later arrivals implying, at least, that there must be high-velocity contrast interfaces under COR. The Puget Sound model inferred from the earthquake study produces conversions and reverberations which are too severe compared to the data. This indicates that the details of the Puget Sound structure, assuming it is correct, do not extend to COR, a not totally unexpected result considering the geologic heterogeneity of the region. 
An apparent paradox is raised by these model investigations. How can the model inferred from long-range refraction (Berg et al., 1966), and supposedly appropriate for COR, be consistent with the need for a high-contrast interface to produce large amplitude conversions and reverberations? The answer to this question can be found by examining the travel times of the observed phases.

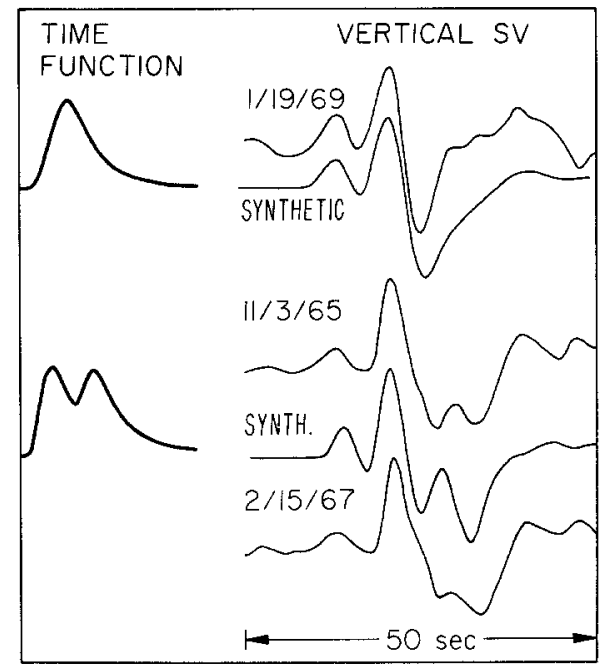

FIG. 5. Comparison of observed and synthetic for the vertical $S V$ component from three earthquakes. Same as Figure 3.

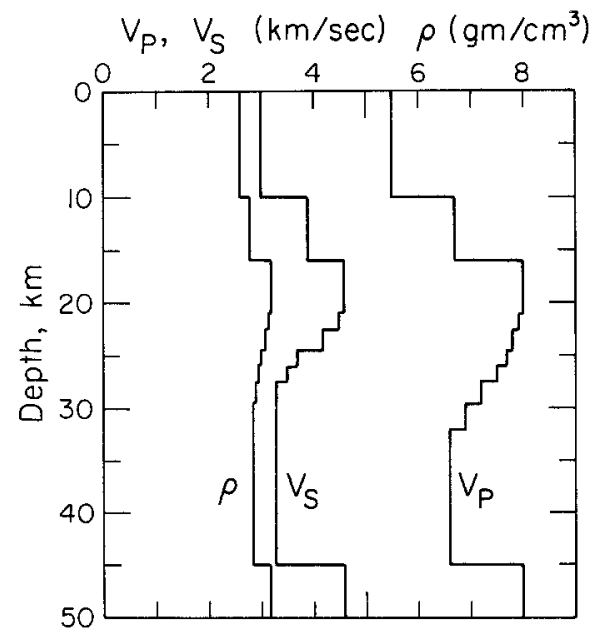

Fig. 6. Final Corvallis erust and upper mantle model.

An average travel time of $7.3 \mathrm{sec}$ for $S p$ relative to direct $S$ can be obtained from the three vertical $S V$ components in Figure 5. The estimated reading error is about \pm 1 sec. The change in travel time due to differing ray parameters is negligible for these ranges. A second $S$ minus $P$ time can be estimated from the $P s$ phase which is very prominent on the radial $P$-wave component. Using the radial $P$ observations of Figure 3 this travel time comes out to be 6.8 sec, relative to direct $P$. The Corvallis model synthetic calculation of Figure 2 has these phases identified for reference. The 
consistency between the $P s-P$ and $S-S p$ times is excellent and supports the contention that these phases originate from the same layer interface.

Assuming Berg's crustal structure and upper mantle velocity (see Table 1) and using the measured $S-P$ times, assuming an average Poisson ratio of 0.25 , yields a depth to the interface of about $65 \mathrm{~km}$, a very remarkable result. However, unless unreasonably high upper mantle velocities exist under Corvallis to create the necessary shear-velocity contrast of 1.0 to $1.5 \mathrm{~km} / \mathrm{sec}$ a velocity inversion must take place between the moho of Berg's model and the interface. This contrast was estimated using ray theory and the relative amplitudes of $S p(1 / 19 / 69$ event) and $P s(12 / 27 / 67$ event).

Fortunately, there are other model constraints which can be found directly from the teleseismic data. Since the contrast is large, as inferred from the relative amplitude of the converted phases, it is very reasonable to expect large reverberations also. In particular, if the first $P$ multiple could be observed it would be extremely useful in constraining the average $P$ velocity between the interface and free surface, assuming normal mantle velocities below the interface and using the estimated contrast. This phase is indeed observable and is shown in Figures 3 and 4. Also apparent is an interesting azimuthal dependence for this phase. For the four earthquakes in the southeast $(9 / 9 / 67,12 / 27 / 67,11 / 3 / 65,2 / 15 / 67)$ this $P$ reverberation is very prominent. For the other two events situated to the northwest $(1 / 19 / 69,1 / 29 / 71)$ the phase is very weak or missing. There is a possibility that dipping or discontinuous structure might cause this, but this is not supported by the excellent $S p$ and $P s$ observations of the $1 / 19 / 69$ event. A more reasonable possibility is a near-surface effect in which the effective reflection coefficient at the surface is modified by the geology. The bounce points for the southeastern events are in the alluviated Willamette Valley which would tend to cause relatively large $P$ reflections. The northwest azimuths, however, contain outcrops of Eocene basalts (Bromerly and Snavely, 1964) whose higher velocities could conceivably reduce the free-surface reflection coefficient or cause scattering. These speculations only illustrate that the model assumptions start to break down when multiples are considered.

Other problems arise from this phase interpretation. For example, the $11 / 3 / 65$ and $2 / 15 / 67$ event are at a range $\left(\Delta=71^{\circ}\right)$ where $P c P$ arrives very close to the inferred multiple time making the interpretations ambiguous for these events. To prove the existence of the $P$ multiple a comparison was made of two earthquakes recorded at both COR and Longmire, Washington (LON, see Figure 1). A qualitative examination of the horizontal and vertical $P$ waves revealed that the LON structure was more subdued in terms of large-contrast interfaces as compared to COR. LON is less than $200 \mathrm{~km}$ from COR which should have a negligible effect on waveshapes from teleseismic sources due to azimuthal variations in the radiation pattern. Figure 7 displays the comparison for the $12 / 27 / 67$ and $9 / 9 / 67$ events. This comparison demonstrates that the arrival is indeed a local structure effect and not due to the source.

An average travel time of $12 \mathrm{sec}$ is obtained for this phase using the vertical $P$ components of Figures 3.3 and 3.4. If the reasonable assumption is used that this phase reflects off the same interface which produces the conversions (otherwise there would be twice as many arrivals), some very interesting results are obtained on material properties of the COR upper mantle. Using a simplification of Berg's model for the velocities in the crust and uppermost mantle along with the inferred average 
travel times for the converted phases implies shear velocities approximately half as large as $P$ velocities. This corresponds to an average Poisson ratio, $\sigma$, of at least 0.33 using

$$
\sigma=\frac{\alpha^{2}-2 \beta^{2}}{2\left(\alpha^{2}-\beta^{2}\right)}
$$

This unusual material property coupled with the large velocity contrasts needed to produce the prominent phase conversions suggests strongly that a major low-velocity zone exists under Corvallis.

The Corvallis model displayed in Figure 3.6 was a result of modeling the $P$ waves from the $12 / 27 / 67$ event and the vertical $S V$ wave from the $1 / 19 / 69$ event. These particular earthquakes were used on the basis of the simplicity of their inferred time functions. The absolute velocities of the LVZ and lowermost mantle in the Corvallis model are not constrained quantities and could vary by $\pm 0.5 \mathrm{~km} / \mathrm{sec}$ without sig nificantly changing the conclusions. The gradients at the top of the LVZ were put

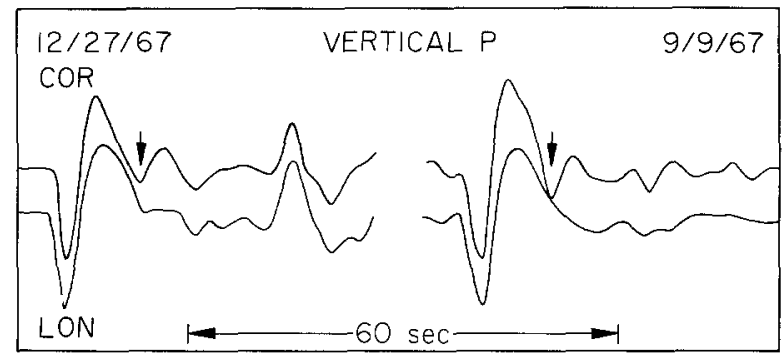

FIa. 7. Comparison of the vertical $P$ components for two earthquakes as recorded at both LON (bottom) and COR (top). The arrows designate the arrival time of the first $P$ multiple for COR.

in to minimize $S P$ conversions which are not observable in the data. The density profile is assumed and may be changed without much detriment to the fits. It does help the overall contrast at the bottom interface, however, and because of the large velocity contrasts, is reasonable. The details of the gradients can also be changed and are not unique as long as the contrast at the bottom interface and average $S$ and $P$ travel times are satisfied.

It was found that using the simplest events for the earth modeling procedure was sufficient to explain all other wave forms in the data set once an estimate of each source time function was known. For example, the vertical-radial comparisons of Figure 3.3 worked remarkably well for the time functions obtained from just the vertical components. The interference and relative amplitude behavior of $P s$ relative to $P$ was found to be a sensitive function of incident pulse shape and justifies the careful search for relatively simple earthquakes.

It is interesting to note how well the reverberations after $P s$, Figure 3.3, were fit both in timing and periodicity. These particular phases were not used to constrain the earth model but fell naturally from it once the observed time and amplitude of the direct conversions were matched. Note that these reverberations are composed of mixed mode rays and contain independent constraints on the average Poisson ratio and velocity contrasts at depth. Taken with the interpretation of the primary 
conversions and first $P$ reverberation, these reverberations add to the consistency of the assumptions and interpretations used in the modeling procedure.

The vertical $S V$ waves for the $11 / 3 / 65$ and $2 / 15 / 67$ events represent what can happen to amplitude and wave-form studies which use a relatively complicated event. Burdick and Helmberger (1974) studied the 11/3/75 earthquake and concluded that it was a multiple source from a deconvolution technique. Jordan and Frazier (1975) used this source in their interpretation of $S p$ precursors in the Grenville province of Canada. They observed a source time separation of about $6 \mathrm{sec}$ and discovered that this source function introduced some ambiguity into their results due to the interference of the multiple peaks. The bottom time function of Figure 3.5 uses the time separation inferred by Jordan and Frazier. The resultant total response, although not perfect, clearly shows the complications introduced in the $S p$ to $S$ amplitude ratios and the later arrivals in the wave form. The $2 / 15 / 67$ observation is also shown with the $11 / 3 / 65 S V$ synthetic. The vertical $P$ waves showed similarities to each other in terms of multiple arrivals but were somewhat different in width (Figure 3.3). Because of this and the almost identical behavior of the vertical $S V$ waves it was concluded that this event too was a multiple source.

\section{Discussion}

Although the Corvallis and Puget Sound earth models differ in detail, their remarkable general similarity strongly suggests that the LVZ may be a regional characteristic. Furthermore, this agreement lends support and justification for using earthquake sources for detailed structure determinations, opening a previously untapped source of data. It also appears that the straightforward methods used in the receiver structure determination may be superior to that of spectral interpretations since it is very easy to work with isolated phases.

The major low-velocity zones discovered here are not without independent supporting evidence. Some of the most direct evidence comes from the refraction profiles of Berg et al. (1966) and Johnson and Couch (1970). In the first case, a well-developed $P n$ wave was observed to ranges of about $130 \mathrm{~km}$ where it suddenly disappeared. These authors admit several possibilities which include negative velocity gradients. Johnson and Couch (1970) interpreted the disappearance of $P n$ at the end of their unreversed profile across the Cascades into Puget Sound as the effect of anelastic attenuation. Again, a negative velocity gradient would accomplish the same effect. The great negative isostatic gravity anomaly centered over Puget Sound of Daneš (1969) suggests a very unusual density profile at depth which could conceivably be a result of a LVZ. In a study of absolute $P$ residuals from the CANNIKIN blast across the Olympic Mountains and Puget Sound, Lin (1974) stated that the relatively slow residuals observed in the Puget lowlands could be explained by the thickening of a LVZ.

Although it is very tempting to speculate on the geophysical implications of these low-velocity zones, their interpretation should wait until other regional stations are studied in the manner of COR. As demonstrated in the discussions of Jordan and Frazier (1975), who found a similar result in Canada, petrological arguments yield no useful constraints or unambiguous interpretations.

\section{CONCLUSIONS}

From modeling the horizontal and vertical $P$-wave components and vertical $S V$ component from recordings of teleseismic sources at COR a distinct LVZ is inferred, 
qualitatively substantiating the results of Langston and Blum (1976) and suggesting that it may be a regional phenomenon. The amplitude and timing of $S p, P s$, and the first $P$ multiple suggest a bottom LVZ interface contrast for $P$ and $S$ velocities of about 1.4 and $1.3 \mathrm{~km} / \mathrm{sec}$, respectively, and a depth of $45 \mathrm{~km}$. The Poisson ratio for material in the LVZ is constrained by the travel times of these phases and has an unusually high value of 0.33 . Changes in the absolute velocities of the Corvallis model are possible but are required to satisfy the large contrast and high average Poisson ratio.

Using a data set composed of several different teleseismic earthquakes for direct time-domain modeling is a useful way to approach the one station method for crustal and upper mantle structure determinations. Although the effective source function is an unknown for most earthquakes, a suitable choice of several simple, deep and intermediate-depth events, based on the complexity of the observed vertical $P$ wave, allows for straightforward manipulation and interpretation of the data.

Simultaneous source and structure modeling for simple earthquakes combined with receiver structure studies may prove to be a very useful reconnaissance tool in regions of the world where other geophysical studies are lacking or where most techniques fail. Convergence zones with many intermediate depth earthquakes would be most amenable to these techniques since these areas are often isolated with poor local station coverage.

\section{ACKNOWLEDGMENTS}

This research was supported by the Advanced Research Projects Agency of the Department of Defense and was monitored by the Air Force Office of Scientific Research under Contract F44620-72-C-0078 and by the National Science Foundation Grant EAR 76-06619.

\section{REFERENCES}

Båth, M. and R. Stefánsson (1966). S-P conversion at the base of the crust, Ann. Geofis., (Rome) $19,119-130$.

Berg, J. W., L. T. Trembly, D. A. Emilla, J. R. Hutt, J. M. King, L. T. Long, W. R. MeKnight, S. K. Sarmah, R. Souders, J. V. Thiruvathukal, D. A. Vossler (1966). Crustal refraction profile, Oregon Coast Range, Bull. Seism. Soc. Am. 56, 1357-1362.

Bonjer, K. P., K. Fuchs, and J. Wohlenberg (1970). Crustal structure of the East African rift system from spectral response rations of long-period body waves, $Z$. Geophys. 36, 287-297.

Bromery, R. W. and P. D. Snavely, Jr. (1964). Geologic interpretation of reconnaissance gravity and aeromagnetic surveys in northwestern Oregon, U.S. Geol. Surv. Bull. 1181-N.

Burdick, L. J. and D. V. Helmberger (1974). Time functions appropriate for deep earthquakes, Bull. Seism. Soc. Am. 64, 1419-1428.

Burdiek, L. J. and C. A. Langston (1976). Modeling erustal structure through the use of converted phases in teleseismic body wave forms, Bull. Seism. Soc. Am. 67, 677-691.

Carpenter, E. W. (1966). Absorption of elastic waves-an operator for a constant $Q$ mechanism, $A W R E$ Report No. $0-43 / 66, \mathrm{H}$. M. Stationery Office.

Daneš, Z. F. (1969). Gravity results in western Washington, EOS 50, 348-350.

Fernandez, L. M. (1967). Master curves for the response of layered media to compressional seismic waves, Bull. Seism. Soc. Am. 57, 515-543.

Fernandez, L. M. and J. Careaga (1968). The thickness of the crust in crustal United States and La Paz, Bolivia, from the spectrum of longitudinal seismic waves, Bull. Seism. Soc. Am. 58, $711-741$.

Hannon, W. J. (1964). An application of the Haskell-Thomson matrix method to the synthesis of the surface motion due to dilatational waves, Bull. Seism. Soc. Am. 54, 2067-2079.

Haskell, N. A. (1960). Crustal reflection of plane $S H$ waves, J. Geophys. Res. 65, 4147-4150.

Haskell, N. A. (1962). Crustal reflection of plane $P$ and $S V$ waves, $J$. Geophys. Res. 67, 4751-4767.

Helmberger, D. V. (1968). The crust-mantle transition in the Bering Sea, Bull. Seism. Soc. Am. 58, 179-214. 
Johnson, S. H. and R. W. Couch (1970). Crustal structure in the north Cascade Mountains of Washington and British Columbia from seismic refraction measurements, Bull. Seism. Soc. Am. 60, 1259-1269.

Jordan, T. H. and L. N. Frazier (1975). Crustal and upper mantle structure from $S p$ phases, $J$. Geophys. Res. 80, 1504-1518.

Kurita, T. (1973a). A procedure for elucidating fine structure of the crust and upper mantle from seismological data, Bull. Seism. Soc. Am. 63, 189-209.

Kurita, T. (1973b). Regional variation in the structure of the erust in the central United States from $P$-wave spectra, Bull. Seism. Soc. Am. 63, 1663-1687.

Langston, C. A. (1977). The effect of planar dipping structure on source and receiver responses for constant ray parameter, Bull. Seism. Soc. Am. 67, (in press).

Langston, C. A. and D. E. Blum (1977). The April 29, 1965, Puget Sound earthquake and the crustal and upper mantle structure of western Washington, Bull. Seism. Soc. Am. 67, 693-711.

Leblanc, G., S. J. (1967). Truncated crustal transfer functions and fine crustal structure determination, Bull. Seism. Soc. Am. 57, 719-733.

Leong, L. S. (1975). Crustal structure of the Baltic shield beneath Umea, Sweden, from the spectral behavior of long-period $P$ waves, Bull. Seism. Soc. Am. 65, 113-126.

Lin, J. W. (1974). A study of upper mantle structure in the Pacific Northwest using $P$ waves from teleseisms, Ph.D. Theses, Univ. of Washington, $98 \mathrm{pp}$.

Phinney, R. A. (1964). Structure of the Earth's crust from spectral behavior of long-period body waves, $J$. Geophys. Res. 69, 2997-3017.

Snavely, P. D. and H. C. Wagner (1963). Tertiary geologic history of western Oregon and Washington, Div. Mines Geol. Report of Invest. 22, 25 pages.

White, W. R. H. and J. C. Savage (1965). A seismic refraction and gravity study of the Earth's crust in British Columbia, Bull. Seism. Soc. Am. 55, 463-486.

Smismological Laboratory

Division of Geological and Planetary Sciences

California Institute of Technology

Pasadena, California 91125

Division of Geological and Planetary Sciences

Contribution No. 2827

Manuscript received September 23, 1976 